\title{
Template electrosynthesis of $\mathrm{La}(\mathrm{OH})_{3}$ and $\mathrm{Nd}(\mathrm{OH})_{3}$ nanowires using porous anodic alumina membranes
}

\author{
P. Bocchetta *, M. Santamaria, F. Di Quarto \\ Dipartimento di Ingegneria Chimica dei Processi e dei Materiali, Università di Palermo, Viale delle Scienze, 90128 Palermo, Italy \\ Received 5 October 2006; received in revised form 30 October 2006; accepted 30 October 2006 \\ Available online 28 November 2006
}

\begin{abstract}
High quality arrays of $\mathrm{Ln}(\mathrm{OH})_{3}(\mathrm{Ln}=\mathrm{La}, \mathrm{Nd})$ nanowires have been successfully fabricated for the first time by an electrochemical process using anodic alumina membrane templates. A physico-chemical characterisation of electrodeposited hydroxides has been carried out by different techniques (XRD, SEM and EDX). The results show that the synthesized nanostructures are crystalline, dense, continuous, well aligned, and with high aspect ratio, suggesting further development of possible applications in the lanthanide family species. (C) 2006 Elsevier B.V. All rights reserved.
\end{abstract}

Keywords: Nanowires; Anodic alumina membranes; Hydroxide electrodeposition; Template; Lanthanide compounds

\section{Introduction}

Lanthanide oxides $\left(\mathrm{Ln}_{2} \mathrm{O}_{3}\right)$ are widely used as luminescent materials [1] and as catalysts or catalysts modifiers [2-7]. If we consider that these properties can be enhanced by producing nanostructured materials with a large surface/volume ratio and that $\mathrm{Ln}_{2} \mathrm{O}_{3}$ can be prepared by a dehydration process of the corresponding rare earth metal hydroxide [8], the possibility to find an easy route for fabricating a continuous pattern of $\operatorname{Ln}(\mathrm{OH})_{3}$ nanowires seems really appealing. The synthesis of lanthanide hydroxides nanowires through a solution-based hydrothermal process has been recently reported in the literature [9-12]. According to this method, amorphous $\mathrm{Ln}(\mathrm{OH})_{3}$ is precipitated by drastically increasing the $\mathrm{pH}$ of a $\mathrm{Ln}^{3+}$ containing solution. The precipitate is thermal treated for $12-45 \mathrm{~h}$ at $180{ }^{\circ} \mathrm{C}$ in autoclave and then left to cool to room temperature. A final filtration step is performed in order to collect the crystallized hydroxide, as a disordered ensemble of $\mathrm{Ln}(\mathrm{OH})_{3}$ nanowires with an average diameter of $20-40 \mathrm{~nm}$ and an average length up to $5 \mu \mathrm{m}$.

\footnotetext{
${ }^{*}$ Corresponding author. Tel.: +39091 6567233; fax: +3906233211963. E-mail address: bocchetta@dicpm.unipa.it (P. Bocchetta).
}

Template-directed synthesis [13] utilizing anodic alumina membrane (AAM) [14-17] has become a popular pathway to produce nanometric-size materials [18] of different nature (metals, semi-conductors, polymers and oxides), and for different applications. The successful use of AAMs in this field is related to: (a) easy and low-cost fabrication method, (b) benefits of a high pore densities in a hexagonal highly ordered close-packed arrays $[19,20]$, (c) ability to tailor pore diameters and depths by simply controlling the anodizing conditions of aluminium [21-25].

Moreover deposition into the pores using direct current (dc) electrodeposition, instead of other conventional methods (i.e. chemical vapour deposition, electroless or sol-gel deposition) has proven to be a particularly powerful technique, enabling substantial control over composition and crystallinity, easy access to compositional modulation along the wire lengths, and possibility to grow high aspect ratio nano-structures due to the field-assisted migration of ions into channels of AAMs.

In this work, we study the possibility to use an electrochemical route for the synthesis at room temperature of $\mathrm{La}(\mathrm{OH})_{3}$ and $\mathrm{Nd}(\mathrm{OH})_{3}$ by electrogeneration of base through the cathodic reduction of $\operatorname{Ln}\left(\mathrm{NO}_{3}\right)_{3}$ solution [26]. Moreover, we show how the use of anodic alumina 
membrane (AAM) as a template for the direct synthesis of lanthanide hydroxides allows to get ordered and high aspect ratio arrays of high quality $\mathrm{Ln}(\mathrm{OH})_{3}$ nanowires.

\section{Experimental}

Commercial anodic alumina membranes (AAM) (Anodisc-60 Whatman, $25 \mathrm{~mm}$ diameter) with pore diameters of approximately $200 \mathrm{~nm}$ and an estimated porosity of $43 \%$, have been employed as template. The dc sputtering technique was used to create a porous gold conducting layer at one side of the membrane. We have to mention that the Au sputtering does not occlude the pores of anodic alumina membranes, thus the initial electrodeposition takes place at the bottom of alumina pores producing a continuous thin film of hydroxide. $\operatorname{Ln}(\mathrm{OH})_{3}$ can subsequently grow continuously toward the top of the pores. The presence of the hydroxide layer at the bottom of the nano-structure is beneficial because it allows to get a freestanding structure of nanowires after the removal of the alumina support (see below). The AAM was supported in a holder in order to delimit the electrode area exposed to the solution $\left(2.54 \mathrm{~cm}^{2}\right)$ and to perform the electric contact with a $\mathrm{Cu}$ disk.

The electrodeposition process of $\mathrm{Ln}(\mathrm{OH})_{3}(\mathrm{Ln}=\mathrm{La}$, $\mathrm{Nd}$ ) nanowires was carried out in aqueous $0.05 \mathrm{M}$ $\mathrm{Ln}\left(\mathrm{NO}_{3}\right)_{3}$ solution with slight stirring, by applying a constant current density of $1 \mathrm{~mA} \mathrm{~cm}^{-2}$ with a multichannel potentiostat VMP2 (Princeton Applied Research). A classic three-electrode cell was employed with the AAM as working electrode, a DSA (Dimensionally Stable Anode) electrode as counter electrode and a saturated calomel electrode (SCE) as reference electrode. The pore-filling process has been sometimes followed by a chemical etching in $1 \mathrm{M}$ $\mathrm{NaOH}$ in order to remove the alumina host and release the array of $\mathrm{Ln}(\mathrm{OH})_{3}$ wires.

Morphology and quality of composites AAM/Ln $(\mathrm{OH})_{3}$ and liberated $\mathrm{Ln}(\mathrm{OH})_{3}$ nanowires were investigated by using a Philips XL30 ESEM Scanning Electron Microscope (SEM), by analysing both surfaces and cross sections. EDX analysis was also performed in order to identify the $\mathrm{La}$ and $\mathrm{Nd}$ elements into the hydroxide structure.
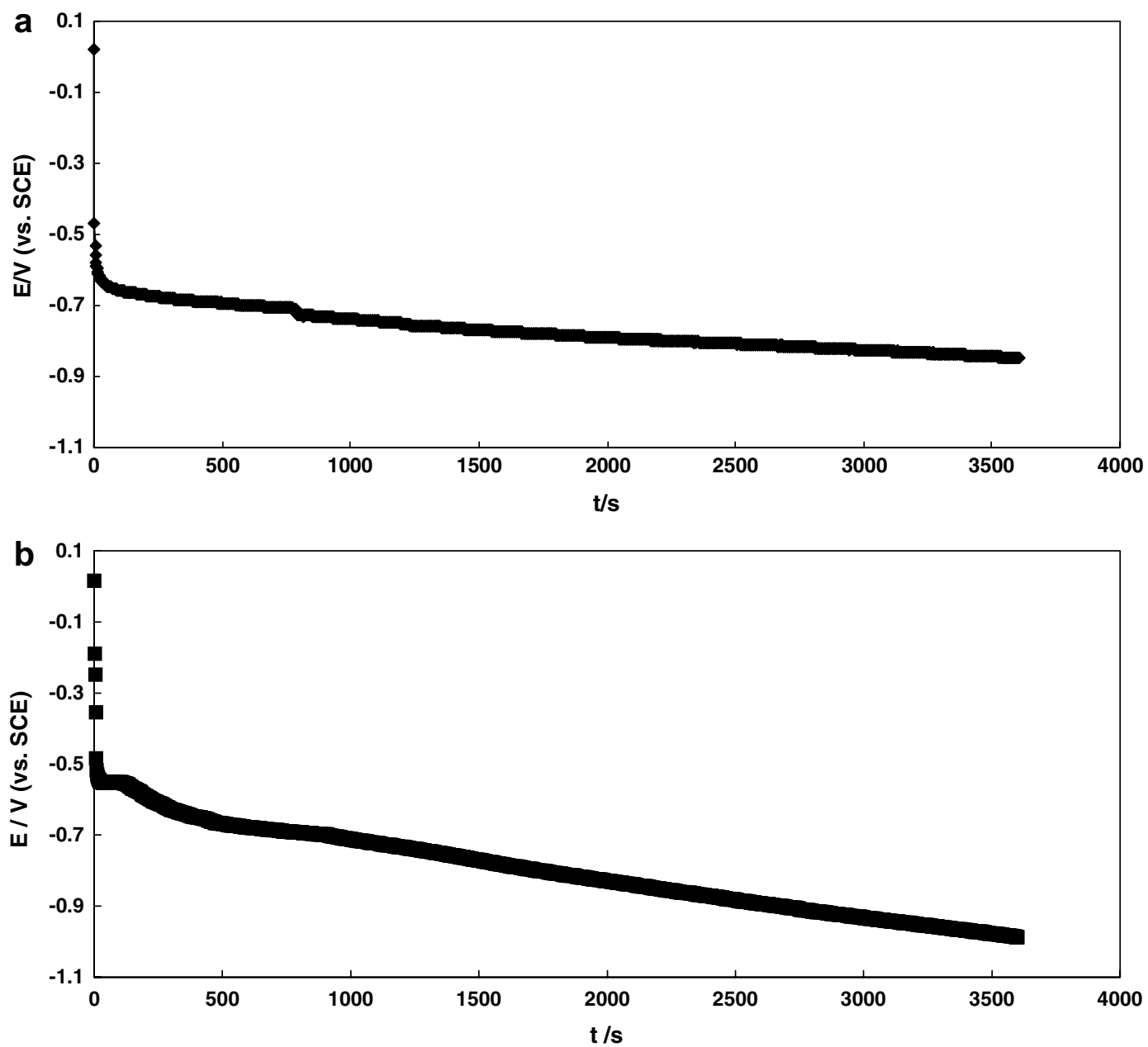

Fig. 1. Potential (Ref. SCE) vs. time curve during the electrodeposition of $\mathrm{La}(\mathrm{OH})_{3}$ (a) and $\mathrm{Nd}(\mathrm{OH})_{3}$ (b) nanowires inside porous $\mathrm{AAM}$ at constant current density. Experimental conditions: $i=1 \mathrm{~mA} \mathrm{~cm}{ }^{2}$ in $0.05 \mathrm{M} \mathrm{Ln}\left(\mathrm{NO}_{3}\right)_{3}$ stirred solution. 
X-ray analysis of nanowires arrays was performed by a Philips X-ray Generator (Model PW 1130) and a PW (Model 1050) goniometry. The identification was performed according to the ICDD (The International Centre for Diffraction Data $\left.{ }^{\circledR}\right)$ available cards.

\section{Results and discussion}

$\mathrm{La}(\mathrm{OH})_{3}$ and $\mathrm{Nd}(\mathrm{OH})_{3}$ were deposited at the cathode trough a mechanism of base electrogeneration in nitrate solution [26], according to a possible reaction:

$\mathrm{NO}_{3}^{-}+\mathrm{H}_{2} \mathrm{O}+2 \mathrm{e}^{-} \rightarrow \mathrm{NO}_{2}^{-}+2 \mathrm{OH}^{-}$

having a standard equilibrium potentials of $-0.23 \mathrm{~V}$ (SCE). In our operating conditions (initial $\mathrm{pH} 3$ and by assuming $\mathrm{NO}_{2}^{-}=10^{-6} \mathrm{M}$ ) an equilibrium potential of $0.57 \mathrm{~V}$ (SCE) has been estimated. The local increase of $\mathrm{pH}$, owing to the production of hydroxyl ions according to Eq. (1), leads close to cathodic area to the precipitation of the rare earth metal hydroxide, as:

$$
\mathrm{Ln}^{3+}+3 \mathrm{OH}^{-} \rightarrow \mathrm{Ln}(\mathrm{OH})_{3} \downarrow
$$

once the concentration of $\mathrm{OH}^{-}$ions is so high that $\left[\mathrm{Ln}^{3+}\right] \times\left[\mathrm{OH}^{-}\right]^{3}$ is higher than the solubility constant, $K_{\mathrm{S}}$.

As shown in Fig. 1, after an initial voltage drop from the open circuit potential to $-0.6 \mathrm{~V}$ (SCE), the electrode poten-
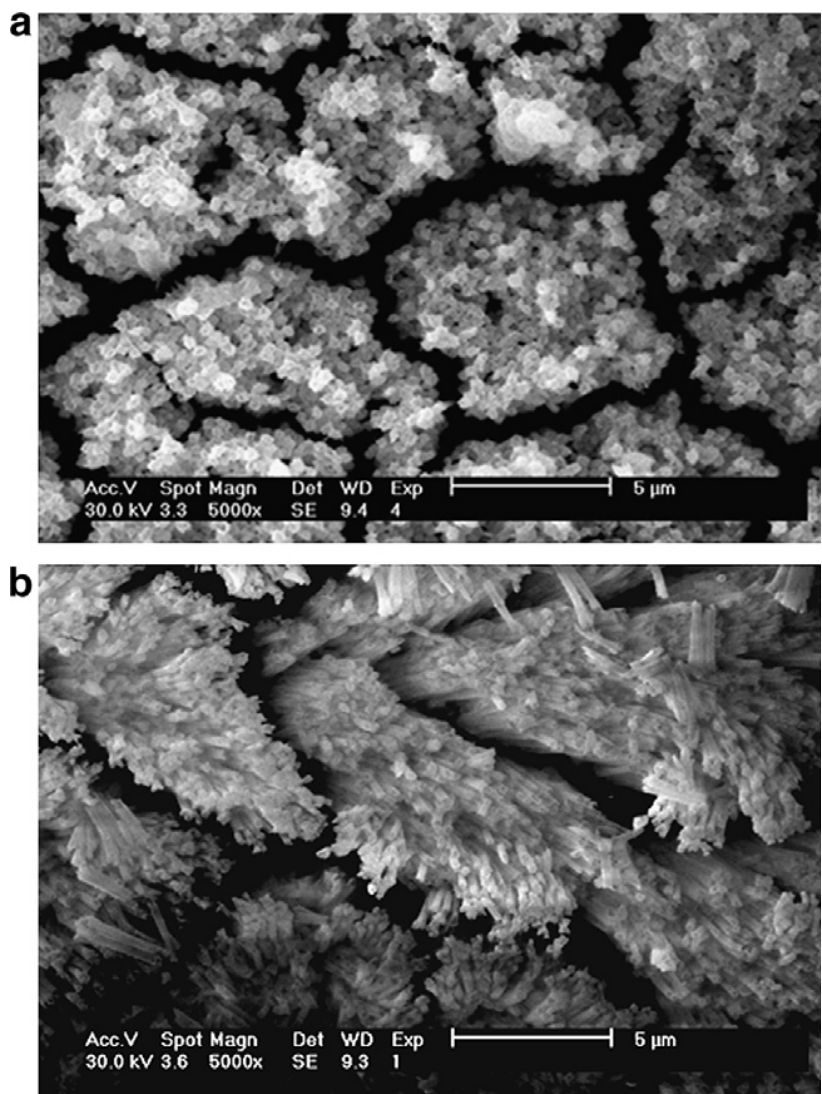

Fig. 2. Typical top front SEM images of $\mathrm{La}(\mathrm{OH})_{3}$ (a) and $\mathrm{Nd}(\mathrm{OH})_{3}$ (b) nanowires arrays after removal of the template membrane by chemical etching in $1 \mathrm{M} \mathrm{NaOH}$ solution. tial decreases almost linearly during the deposition process. The increasing overvoltage that sustains the process is presumably related to the thickening of the deposits, i.e. to the increasing nanowires length, which introduces a further increasing contribution to the total IR drop of the nitrate ions reduction process inside the alumina pores. According to Ohm's law, the ohmic voltage drop $\Delta E$, across the rod, and the current intensity $I$ are linearly related and at constant current density the $\Delta E$ contribution due to the formation of hydroxide nanowires can be written as:

$\Delta E=I \Delta R=I \frac{\Delta l}{S} \rho=i \rho \Delta l$

where $i$ is the effective current density, $\rho$ the $\mathrm{Ln}(\mathrm{OH})_{3}$ resistivity and $\Delta l$ the wires length. By assuming a constant current efficiency, during the electrodeposition process at constant current, a linear increase of nanorod length with electrodeposition time is expected (see Fig. 1).

Due to the high cathodic potential reached during the deposition, the hydrogen evolution reaction at first glance appears thermodynamically possible. However owing to the large change in $\mathrm{pH}$ values near the cathodic area and to the high ohmic drop into the alumina pores, the discharge of hydrogen is practically forbidden. Moreover, this suggestion is confirmed by the morphological analysis (see below), which does not evidence any damage to the deposit due to the presence of gas evolution. Finally, we can exclude the formation of lanthanide reduction products,
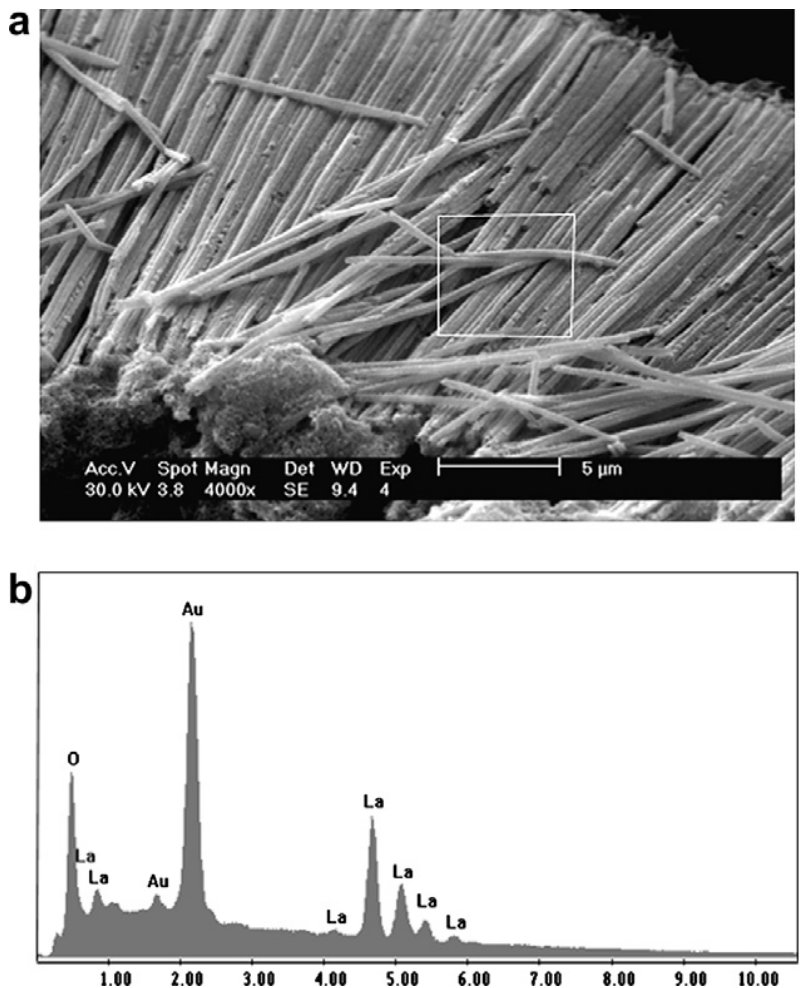

Fig. 3. (a) SEM image of the cross-sections of free-standing $\mathrm{La}(\mathrm{OH})_{3}$ nanowires after removal of the template membrane by chemical etching in $1 \mathrm{M} \mathrm{NaOH}$ solution. (b) EDX spectrum performed in the area indicated in (a). 
since according to the Pourbaix diagrams for the systems $\mathrm{La}-\mathrm{H}_{2} \mathrm{O}$ and $\mathrm{Nd}-\mathrm{H}_{2} \mathrm{O}$ at room temperature [27], the equilibrium potentials for the process $\mathrm{Ln}^{3+}+3 \mathrm{e}^{-} \rightarrow \mathrm{Ln}$ are sensibly more cathodic than those measured during the electrodeposition.

A typical SEM image of the nanowires top front after removal of the template membrane by chemical etching in $1 \mathrm{M} \mathrm{NaOH}$ is reported in Fig. 2, while in Figs. 3a and 4a the cross-sections of free-standing nano-structures without alumina template show that the nanowires grow highly homogeneous in shape, are continuous and uniform throughout the entire length and arranged roughly parallel to each other. These characteristics were observed in many different areas of the samples. The broken nanowires visible in the figures are probably formed during the specimens preparation procedure for SEM analysis.

The diameter of the $\mathrm{Ln}(\mathrm{OH})_{3}$ nanowires (around $200 \mathrm{~nm}$ ) is almost coincident to that of the pores of alumina template. The length of the wires results to be approximately $30 \mu \mathrm{m}$ for $\mathrm{La}(\mathrm{OH})_{3}$ and $50 \mu \mathrm{m}$ for $\mathrm{Nd}(\mathrm{OH})_{3}$, which correspond to an aspect ratio of $\sim 150$ and 250 , respectively. We want to stress that pore diameters and thickness of AAM can be easily controlled during the fabrication process [21-25] so allowing, in principle, to reach still larger aspect ratios.

a

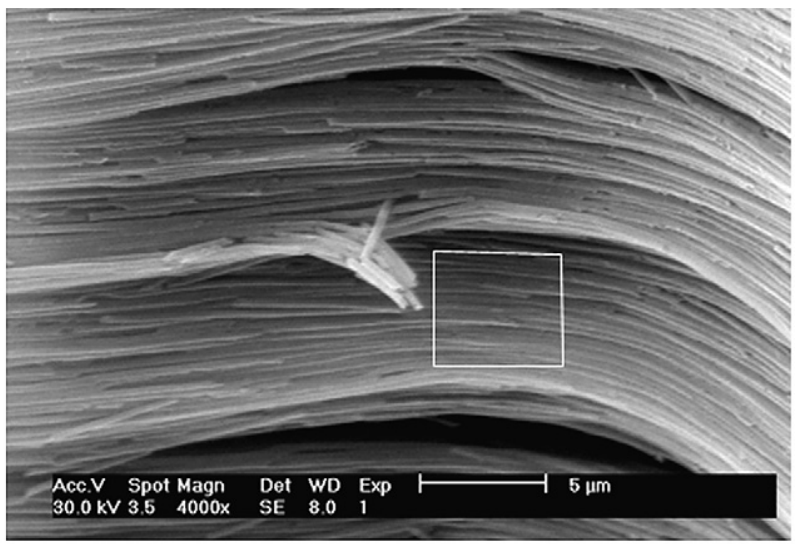

b

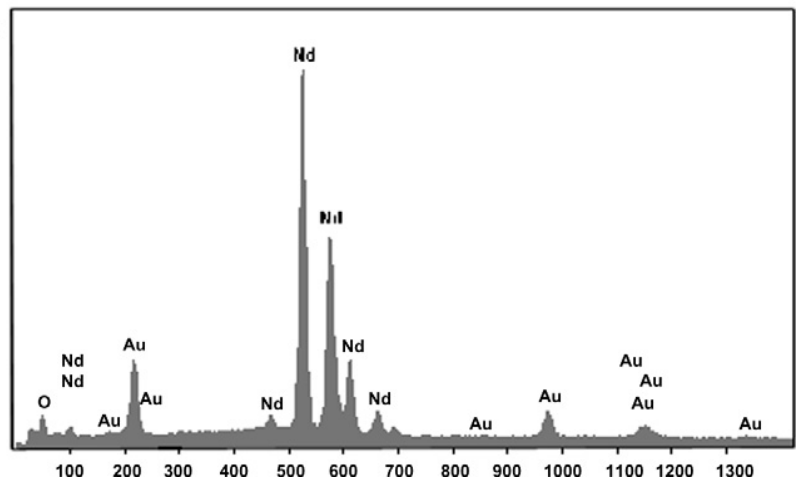

Fig. 4. (a) SEM image of the cross-sections of free-standing $\mathrm{Nd}(\mathrm{OH})_{3}$ nanowires after removal of the template membrane by chemical etching in $1 \mathrm{M} \mathrm{NaOH}$ solution. (b) EDX spectrum performed in the area indicated in (a).
In Fig. 5a we show the SEM photograph of the $\mathrm{La}(\mathrm{OH})_{3}$ layer formed at the bottom of the alumina membrane and, consequently, of the nanowires structure. As better evidenced in the Fig. 5b, the presence of a hydroxide layer allows the nanowires structure to stand without the alumina support.

The individual $\mathrm{Ln}(\mathrm{OH})_{3}$ wires were also observed at higher magnification in order to better verify their morphology. According to Fig. 6, the deposits reproduce the cylindrical shape of the pores, and result not in nanotubes, but in dense, continuous and defect-free nanowires.

In order to exclude possible incorporation of $\left(\mathrm{NO}_{3}\right)^{-}$ species into the ceramic matrix and in the hydroxide, energy dispersive X-ray (EDX) analysis in different areas of the cross-section and surfaces were performed. In Figs. $3 \mathrm{~b}$ and $4 \mathrm{~b}$ we report the EDX analysis of areas indicated in Figs. 3a and 4a, respectively. Only the rare earth metal, oxygen and gold are revealed. It is important to stress that the Au element peaks in the spectra are due to the gold sputtered on the sample in order to enhance their conductivity for a better SEM characterization.

Fig. 7 depicts the XRD patterns of $\operatorname{Ln}(\mathrm{OH})_{3}$ nanowires embedded inside porous AAM. From the X-ray analysis it can be inferred that nanowires are clearly polycrystalline and show hexagonal phase (space group P63m (176)), with lattice constants $a=6.5286, c=3.8588$ for $\mathrm{La}(\mathrm{OH})_{3}$
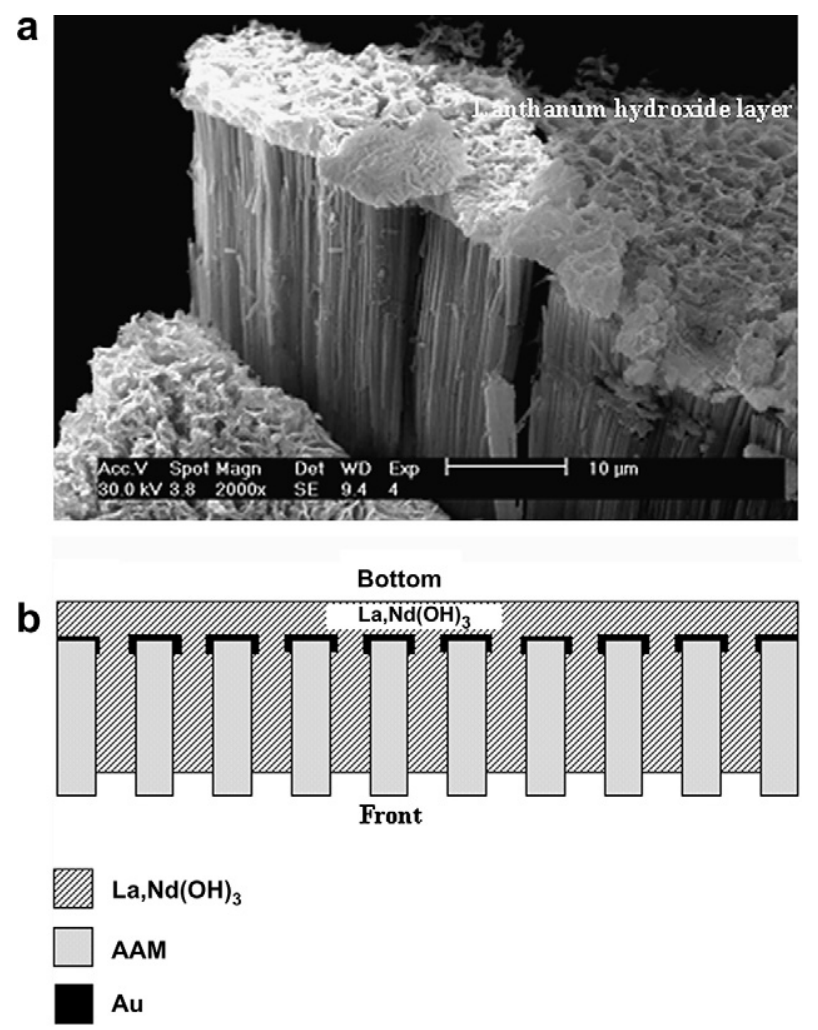

Fig. 5. (a) SEM image of broken $\mathrm{La}(\mathrm{OH})_{3}$ nanowires arrays after removal of the template showing a compact hydroxide layer at the base of the structure. (b) Schematic diagram of the structure of the hydroxides after the electrodeposition process. 


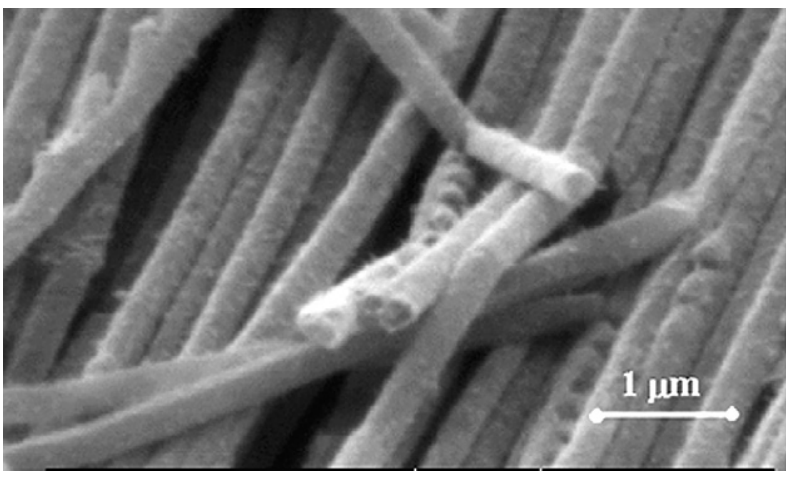

Fig. 6. SEM image of $\mathrm{La}(\mathrm{OH})_{3}$ wires at higher magnification.

(ICDD card 36-1481) and $a=6.418, c=3.743$ for $\mathrm{Nd}(\mathrm{OH})_{3}$ (ICDD card 83-2035). The broad feature in the spectrum arises from the amorphous alumina substrate. Comparing our XRD spectra, recorded in a range of $2 \theta$ values between $10^{\circ}$ and $100^{\circ}$, with the ones reported in [12] for hydrothermal synthesized disordered $\mathrm{Ln}(\mathrm{OH})_{3}$ nanowires, it can be observed the same relative intensity of $100 \%$ for the peak $(1,1,0)$, and the absence of the peaks $(1,0,0),(2,0,0),(2,0,1)$ for the template electro-synthesized
$\mathrm{Ln}(\mathrm{OH})_{3}$ hydroxides. These findings suggest a slight preferential growth of the $\mathrm{Ln}(\mathrm{OH})_{3}$ electrodeposited wires along the directions $(1,1,0)$ and $(0,0,2)$, in agreement with literature where the growth of strongly textured and single-crystal nanowires inside AAMs is often reported [28-30]. The polycrystallinity of the $\mathrm{Ln}(\mathrm{OH})_{3}$ nanowires may be related to the electrodeposition process occurring into pores of wider diameter (about $200 \mathrm{~nm}$ ).

\section{Conclusions}

High quality crystalline $\mathrm{Ln}(\mathrm{OH})_{3}(\mathrm{Ln}=\mathrm{La}, \mathrm{Nd})$ nanowires were assembled into ordered nano-channels of anodic alumina membrane by electrogeneration of base through the cathodic reduction of $\mathrm{Ln}\left(\mathrm{NO}_{3}\right)_{3}$ solution. With respect to the hydrothermal method, the template-assisted electrodeposition is able to produce at room temperature lanthanide hydroxide nanowires with a very ordered structure and a high aspect ratio as evidenced by the SEM analysis performed in this work. The average diameters of the wires obtained with this procedure is around $200 \mathrm{~nm}$ and the average lengths range between 30 and $50 \mu \mathrm{m}$. Further investigations are now in progress in order to evaluate the influence of different electrodeposition parameters on
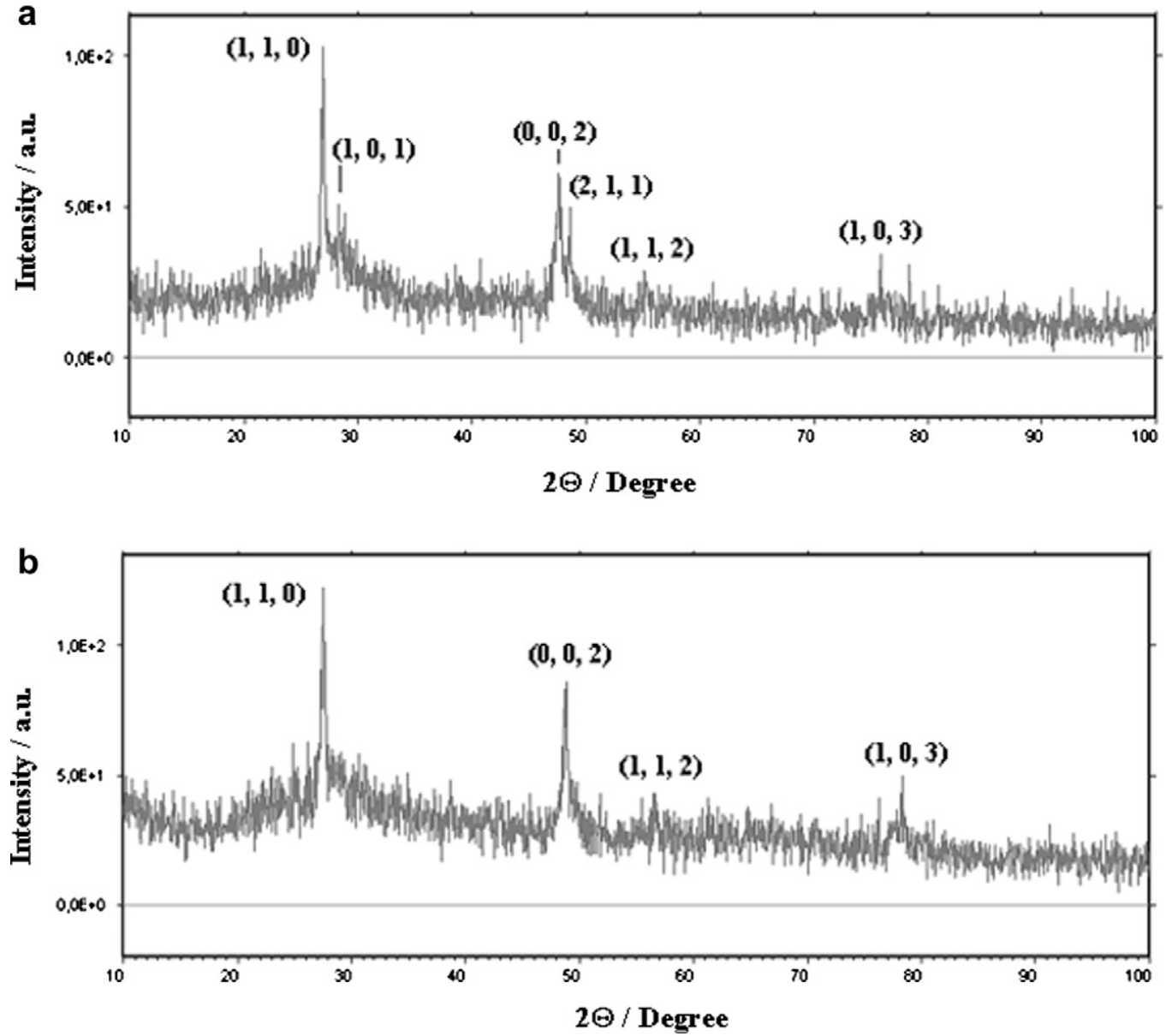

Fig. 7. X-ray diffractograms of electrodeposited $\mathrm{La}(\mathrm{OH})_{3}$ (a) and $\mathrm{Nd}(\mathrm{OH})_{3}$ (b) nanowires inside porous AAM. All reflections in the figure are indexed to hexagonal $\mathrm{Ln}(\mathrm{OH})_{3}\left(\mathrm{ICDD}\right.$ card 36-1481 and 83-2035 for $\mathrm{La}(\mathrm{OH})_{3}$ and $\mathrm{Nd}(\mathrm{OH})_{3}$, respectively). 
the crystalline structure, morphology and size of the $\mathrm{Ln}(\mathrm{OH})_{3}$ nanowires. We hope that the preliminary results above reported could contribute to the development of 1-D lanthanide nanostructures which could be very useful in several technological advanced applications.

\section{Acknowledgement}

This work is supported financially by Università di Palermo. One of the authors (P.B.) is grateful to Università di Palermo for the provision of a fellowship.

\section{References}

[1] R. Bazzi, M.A. Flores-Gonzalez, C. Louis, K. Lebbou, C. Dujardin, A. Brenier, W. Zhang, O. Tillement, E. Bernstein, P. Perriat, J. Lumin. 102-103 (2003) 445.

[2] S.L. Li, S.X. Zhang, H. Hu, Y.H. Zhang, Chinese J. Catal. 25 (2004) 762.

[3] H. Hu, S.L. Li, S.X. Zhang, J. Li, Chinese J. Catal. 25 (2004) 115.

[4] M.S. Palmer, M. Neurock, M.M. Olken, J. Am. Chem. Soc. 124 (2002) 8452.

[5] M.S. Palmer, M. Neurock, M.M. Olken, J. Phys. Chem. B 106 (2002) 6543.

[6] T. Yamamoto, T. Matsuyama, T. Tanaka, T. Funabiki, S. Yoshida, Phys. Chem. Chem. Phys. 1 (1999) 2841.

[7] M.A. Vannice, A.B. Walters, X. Zhang, J. Catal. 159 (1996) 119.

[8] A. Neumann, D. Walters, Thermochim. Acta 445 (2006) 200.

[9] P.X. Huang, B. He, F. Wu, G.L. Pan, X.P. Gao, Chin. J. Inorg. Chem. 22 (2006) 639.

[10] L. Kepinski, M. Zawadzki, W. Mista, Solid State Sci. 6 (2004) 1327.
[11] B. Tang, J. Ge, L. Zhuo, Nanotechnology 15 (2004) 1749.

[12] X. Wang, Y. Li, Angew. Chem. Int. Edit. 41 (2002) 4790.

[13] T.L. Wade, J.E. Wegrowe, Eur. Phys. J. Appl. Phys. 29 (2005) 3.

[14] Y. Piao, H. Lim, J.Y. Chang, W.Y. Lee, H. Kim, Electrochim. Acta 50 (2005) 2997.

[15] C.R. Martin, Science 266 (1994) 1961

[16] D. Al-Mawlawi, C.Z. Liu, M. Moskovits, J. Mater. Res. 9 (4) (1994) 1014.

[17] M. Hernández-Vélez, Thin Solid Films 495 (2006) 51.

[18] C.N.R. Rao, F.L. Deepak, G. Gundiah, A. Govindaraj, Prog. Solid State Ch. 31 (2003) 5 .

[19] O. Jessensky, F. Muller, U. Gosele, J. Electrochem. Soc. 145 (1998) 3735.

[20] H. Masuda, F. Hasegwa, S. Ono, J. Electrochem. Soc. 1445 (1997) L127.

[21] J.W. Diggle, T.C. Downie, C.W. Goulding, Chem. Rev. 69 (1969) 370 .

[22] G.E. Thompson, Y. Xu, P. Skeldon, K. Shimizu, S.H. Han, G.C. Wood, Philos. Mag. B 55 (6) (1987) 651.

[23] P. Bocchetta, PhD Thesis, Politecnico di Milano (2003).

[24] P. Bocchetta, C. Sunseri, G. Chiavarotti, F. Di Quarto, Electrochim. Acta 48 (2003) 3175.

[25] P. Bocchetta, C. Sunseri, A. Bottino, G. Capannelli, G. Chiavarotti, S. Piazza, F. Di Quarto, J. Appl. Electrochem. 32 (2002) 977.

[26] G. Helen Annal Therese, P. Vishnu Kamath, Chem. Mater. 11 (1999) 3561.

[27] M. Pourbaix, Atlas of Electrochemical Equilibria in Aqueous Solutions, Pergamon Press, Oxford, 1966.

[28] J. Oh, Y. Tak, J. Lee, Electrochem. Solid St. 7 (3) (2004) C27.

[29] C. Jia, W. Liu, B. Zhang, C. Jin, L. Yao, W. Cai, X. Li, Chem. Lett. 34 (1) (2005) 20.

[30] D. Routkevitch, T. Bigioni, M. Moskovits, J.M. Xu, J. Phys. Chem. 100 (1996) 14037. 